\title{
Gambaran Stomatitis Aftosa Rekuren pada pengguna alat ortodonsi cekat mahasiswa Program Studi Kedokteran Gigi Universitas Sam Ratulangi
}

\author{
${ }^{1}$ Christy Mintjelungan, ${ }^{2}$ Elita Tambunan, ${ }^{3}$ Priska F. Umboh \\ ${ }^{1}$ Dosen Program Studi Kedokteran Gigi Fakultas Kedokteran Universitas Sam Ratulangi \\ ${ }^{2}$ Dinas Kesehatan Kota Manado \\ ${ }^{3}$ Mahasiswa Program Studi Kedokteran Gigi Fakultas Kedokteran Universitas Sam Ratulangi
}

\begin{abstract}
ABSTRAK
Stomatitis Aftosa Rekuren (SAR) adalah lesi mukosa oral yang timbul secara berulang, biasanya berupa ulser berwarna putih kekuningan. Penggunaan alat ortodonsi cekat merupakan salah satu faktor yang dapat memicu terjadinya SAR. Penelitian ini merupakan penelitian deskriptif, yang bertujuan untuk mengetahui gambaran Stomatitis Aftosa Rekuren pada pengguna alat ortodontik cekat mahasiswa Program Studi Kedokteran Gigi Universitas Sam Ratulangi. Teknik pengambilan sampel yaitu purposive sampling dengan jumlah sampel sebanyak 61 responden. Data hasil penelitian diperoleh berdasarkan kuesioner yang diberikan kepada responden. Hasil penelitian menunjukkan bahwa 80,3\% pengguna alat ortodonsi cekat mahasiswa Program Studi Kedokteran Gigi Universitas Sam Ratulangi pernah mengalami SAR, dimana perempuan lebih cenderung mengalami dibandingkan laki-laki. Lama penggunaan alat ortodonsi cekat berpengaruh terhadap terjadinya SAR. Sebanyak 29,51\% pengguna alat ortodonsi cekat menggunakan alat ortodonsi cekat selama >2tahun, dan sebanyak $36,73 \%$ menyatakan bahwa frekuensi terjadinya SAR terjadi secara tidak teratur. Lokasi terjadinya SAR yaitu pada mukosa pipi $48,98 \%$, mukosa bibir $48,98 \%$, dan lidah $2,04 \%$. Sebanyak $30,61 \%$ responden membiarkan SAR tanpa perawatan dimana 53,33\% responden sembuh $<1$ minggu, $2,04 \%$ berobat ke dokter umum dan sebanyak $67,35 \%$ mengobati sendiri, dimana 57,58\% diantaranya menggunakan obat oles.
\end{abstract}

Kata kunci : Stomatitis Aftosa Rekuren, alat ortodonsi cekat.

\begin{abstract}
Recurrent Aphthous Stomatitis (RAS) can be defined as lesions of the oral mucosa which occours repeatedly, normaly in the form of white yellow ulcer. The using of fixed orthodontic application is one of the factors that trigger RAS to occur. The objective of this research is to discover the description of RAS within the users of fixed orthodontic appliance in dentistry student of Sam Ratulangi University. The sampling method had taken by purposive sampling from 61 sample respondents. The results were gained from the questionnaire that were given to the respondents. The result of this research shows that 80,3\% of the fixed orthodontic appliance users in dentistry student of Sam Ratulangi University ever experienced RAS, by which females tend to experience more than males. Duration of fixed orthodontic application usege is highly influential to the occurrence of RAS. About 29,51\% of the users have been using this fixed orthodontic appliance for $>2$ years, and 36,73\% of them stated the frequency of the occurrence of RAS is irregular. The location where RAS occurs can be describe as 48,98\% in cheek mucosa, 48,98\% in the lips mucosa and 2,04\% in tongue. For the amount of 30,61\% of the users left the SAR untreated, in which 53,33\% of the total respondents admitted healed between $<1$ weeks, 2,04\% seek treatment at the doctor, and 67,35\% treat it by themselves which 57,58\% of them used topical medicine.
\end{abstract}

Keywords : Reccurent Aphthous Stomatitis, fixed orthodontic appliance.

Korespondensi: Priska F. Umboh, Program Studi kedokteran Gigi, Fakultas Kedokteran Universitas Sam Ratulangi, Manado, Indonesia.E-mail: ikhafey@yahoo.com 


\section{PENDAHULUAN}

Stomatitis Aftosa Rekuren (SAR) yang lebih dikenal oleh masyarakat awam dengan "sariawan" merupakan salah satu penyakit mukosa oral yang sering diderita oleh manusia. ${ }^{1}$ Secara klinis SAR memiliki ciri-ciri seperti ulkus dangkal berbentuk bulat atau oval, berwarna putih kekuningan, dan biasanya terjadi pada anak-anak dan remaja yang angka kejadian tertinggi terdapat pada wanita. $^{2,3}$

Ada tiga jenis SAR yang saat ini ditemukan dengan memiliki gejala klinis masing-masing yaitu SAR minor, mayor dan herpetiformis. ${ }^{4}$ Tipe minor paling umum ditemukan, prevalensinya berkisar (80-95\%), SAR tipe mayor (10-15\%), dan SAR tipe herpetiformis $(5-10 \%) .^{5}$ Beberapa penelitian melaporkan prevalensi SAR di negara-negara dengan angka kejadian tertinggi di Amerika Serikat mencapai $60 \%$, Thailand $46,7 \%$, Swedia $2 \%$, Spanyol $1,9 \%$, Malaysia $0,5 \%{ }^{2}$

Faktor-faktor yang bisa menyebabkan timbulnya SAR antara lain karena menyikat gigi, menggigit pipi atau bibir, penggunaan jarum injeksi dalam prosedur dental, perawatan gigi seperti penggunaan gigi tiruan, tambalan yang tajam serta penggunaan alat ortodontik. ${ }^{6,7}$ Penelitian yang dilakukan di Universitas Sumatera Utara menyatakan bahwa faktor yang paling banyak memicu terjadinya SAR adalah trauma dengan prevalensi 50,27\%, sedangkan pada penggunaan alat ortodonsi cekat prevalensinya mencapai $8,33 \%{ }^{8}$ Alat ortodonsi cekat saat ini sudah terkenal di kalangan masyarakat dengan berbagai tujuan pemakaiannya. Beberapa diantaranya menggunakan alat ortodonsi cekat hanya untuk gaya saja dan ada juga yang menggunakannya dengan tujuan memperbaiki maloklusi dan estetik gigi, tanpa mengetahui dampak-dampak dari penggunaan alat tersebut.

Perawatan ortodonsi cekat banyak menggunakan komponen-komponen yang dapat menimbulkan trauma atau iritasi pada jaringan mulut. Hal ini bisa terjadi akibat pemasangan komponen ortodonsi cekat yang kurang baik, seperti pada penggunaan kawat yang terlalu panjang atau komponen lain yang menyebabkan terjadinya trauma, misalnya archwire, ligature wire, loop dan sebagainya. ${ }^{7}$ Stomatitis Aftosa Rekuren yang terjadi pada penderita yang menggunakan alat ortodonsi cekat timbul kemungkinan karena disebabkan oleh trauma, faktor emosi atau psikis. Penderita kadang mengalami stress berulang setiap selesai pengaktivasian alat ortodonsinya karena bracket yang tertekan terus menerus pada mukosa bibir menimbulkan peradangan atau pendarahan dibawah epitel yang menyebabkan lesi eksofilik tanpa fibrosis. ${ }^{7}$ Penelitian ini bertujuan untuk memperoleh gambaran Stomatitis Aftosa Rekuren pada pengguna alat ortodonsi cekat mahasiswa Program Studi kedokteran Gigi Universitas Sam Ratulangi.

\section{BAHAN DAN METODE}

Penelitian ini merupakan penelitian deskriptif dengan menggunakan rancangan penelitian potong lintang (cross-sectional study). Jumlah sampel yang diteliti sebanyak 61 orang dengan teknik pengambilan sampel yang digunakan yaitu purposive sampling.

Pengumpulan data diperoleh berdasarkan kuesioner SAR terhadap penggunaan alat ortodonsi cekat. Responden terlebih dahulu diminta untuk mengisi informed concent, kemudian menjawab pertanyaan-pertanyaan dalam kuesioner penelitian. Data yang diperoleh, diolah dan dianalisis berdasarkan distribusi frekuensi dalam bentuk tabel dan diagram.

\section{HASIL PENELITIAN}

Tabel 1. Distribusi frekuensi responden SAR berdasarkan jenis kelamin.

\begin{tabular}{|c|c|c|c|c|c|c|}
\hline \multirow{5}{*}{$\begin{array}{c}\text { Jenis } \\
\text { Kelamin }\end{array}$} & \multicolumn{4}{|c|}{ Stomatitis Aftosa } & \multirow{3}{*}{\multicolumn{2}{|c|}{ Total }} \\
\hline & \multirow{2}{*}{\multicolumn{2}{|c|}{ (Pernah) }} & \multirow{3}{*}{\multicolumn{2}{|c|}{$\begin{array}{l}\text { (Tidak } \\
\text { pernah) }\end{array}$}} & & \\
\hline & & & & & & \\
\hline & & & & & \multirow[b]{2}{*}{$\mathrm{n}$} & \multirow[b]{2}{*}{$\%$} \\
\hline & $\mathrm{n}$ & $\%$ & $\mathrm{n}$ & $\%$ & & \\
\hline Laki-laki & 7 & 77,78 & 2 & 22,22 & 9 & 100 \\
\hline Perempuan & 42 & 80,77 & 10 & 19,23 & 52 & 100 \\
\hline Total & 49 & 80,3 & 12 & 19,7 & 61 & 100 \\
\hline
\end{tabular}


Tabel 2. Distribusi frekuensi responden berdasarkan lama penggunaan alat ortodonsi cekat

\begin{tabular}{lcc}
\hline \multicolumn{1}{c}{ Lama penggunaan alat ortodonsi cekat } & $\begin{array}{c}\text { Jumlah Responden } \\
(\mathrm{n})\end{array}$ & $\begin{array}{c}\text { Persentase } \\
(\%)\end{array}$ \\
\hline$<1$ bulan & 4 & 6,56 \\
1 - 6 bulan & 9 & 14,75 \\
7 bulan -1 tahun & 14 & 22,95 \\
1 tahun - 2 tahun & 16 & 26,23 \\
$>$ 2 tahun & 18 & 29,51 \\
\hline Total & 61 & 100 \\
\hline
\end{tabular}

Tabel 3. Distribusi frekuensi responden berdasarkan frekuensi munculnya SAR dengan lama penggunaan alat ortodonsi cekat

\begin{tabular}{|c|c|c|c|c|c|c|c|c|c|c|}
\hline \multirow{3}{*}{$\begin{array}{l}\text { Frekuensi } \\
\text { SAR }\end{array}$} & \multicolumn{10}{|c|}{ Lama penggunaan alat ortodonsi cekat } \\
\hline & \multicolumn{2}{|c|}{$<1$ bulan } & \multicolumn{2}{|c|}{ 1-6 bulan } & \multicolumn{2}{|c|}{$\begin{array}{l}7 \text { bulan-1 } \\
\text { tahun }\end{array}$} & \multicolumn{2}{|c|}{ 1-2 tahun } & \multicolumn{2}{|c|}{$>2$ tahun } \\
\hline & $\mathrm{n}$ & $\%$ & $\mathrm{n}$ & $\%$ & $\mathrm{n}$ & $\%$ & $\mathrm{n}$ & $\%$ & $\mathrm{n}$ & $\%$ \\
\hline 2-4 kali & 1 & 25 & & & & & & & & \\
\hline$>5$ kali & & & & & & & 1 & 6,25 & & \\
\hline $\begin{array}{l}>1 \text { kali dalam } \\
\text { sebulan }\end{array}$ & & & & & 3 & 21,43 & 2 & 12,5 & & \\
\hline $\begin{array}{l}\text { Sebulan } \\
\text { sekali }\end{array}$ & & & 1 & 11,11 & 5 & 35,71 & 4 & 25 & 8 & 44,44 \\
\hline $\begin{array}{l}\text { Setahun } \\
\text { sekali }\end{array}$ & & & & & & & & & 6 & 33,33 \\
\hline Tidak teratur & & & 4 & 44,44 & 3 & 21,43 & 7 & 43,75 & 4 & 22,22 \\
\hline Tidak SAR & 3 & 75 & 4 & 44,44 & 3 & 21,43 & 2 & 12,5 & & \\
\hline Total & 4 & 100 & 9 & 100 & 14 & 100 & 16 & 100 & 18 & 100 \\
\hline
\end{tabular}

Tabel 4. Distribusi frekuensi responden berdasarkan waktu munculnya SAR

\begin{tabular}{|c|c|c|}
\hline Waktu munculnya SAR & $\begin{array}{l}\text { Jumlah Responden } \\
\text { (n) }\end{array}$ & $\begin{array}{c}\text { Persentase } \\
(\%)\end{array}$ \\
\hline 2 minggu setelah pemasangan alat & 17 & 34,69 \\
\hline 1 bulan setelah pemasangan alat & 5 & 10,20 \\
\hline 6 bulan setelah pemasangan alat & 3 & 6.12 \\
\hline Tidak teratur & 24 & 48,98 \\
\hline Total & 49 & 100 \\
\hline \multicolumn{3}{|c|}{ Tabel 5. Distribusi frekuensi responden berdasarkan lokasi munculnya SAR } \\
\hline Lokasi munculnya SAR & $\begin{array}{c}\text { Jumlah Responden } \\
(\mathrm{n})\end{array}$ & $\begin{array}{c}\text { Persentase } \\
(\%)\end{array}$ \\
\hline Mukosa pipi & 24 & 48,98 \\
\hline Mukosa bibir & 24 & 48,98 \\
\hline Lidah & 1 & 2,04 \\
\hline Total & 49 & 100 \\
\hline
\end{tabular}


Tabel 6. Distribusi frekuensi responden berdasarkan cara penanganan SAR

\begin{tabular}{lcc}
\hline \multicolumn{1}{c}{ Cara Penanganan } & $\begin{array}{c}\text { Jumlah Responden } \\
(\mathrm{n})\end{array}$ & $\begin{array}{c}\text { Persentase } \\
(\%)\end{array}$ \\
\hline Dibiarkan tanpa obat & 15 & 30,61 \\
Mengobati sendiri & 34 & 67,35 \\
Ke dokter umum & 1 & 2,04 \\
Ke dokter gigi & 0 & 0 \\
\hline Total & 49 & 100 \\
\hline
\end{tabular}

Tabel 7. Distribusi frekuensi responden berdasarkan cara penanganan dibiarkan tanpa obat

\begin{tabular}{lcc}
\hline \multicolumn{1}{c}{ Dibiarkan tanpa obat } & $\begin{array}{c}\text { Jumlah Responden } \\
(\mathrm{n})\end{array}$ & $\begin{array}{c}\text { Persentase } \\
\%\end{array}$ \\
\hline$<1$ minggu & 8 & 53,33 \\
Antara 1 - 2 minggu & 7 & 46,67 \\
$>$ 2 minggu & 0 & 0 \\
\hline Total & 15 & 100 \\
\hline
\end{tabular}

Tabel 8. Distribusi frekuensi responden berdasarkan cara penanganan mengobati sendiri

\begin{tabular}{lcc}
\hline \multicolumn{1}{c}{ Mengobati sendiri } & $\begin{array}{c}\text { Jumlah Responden } \\
(\mathrm{n})\end{array}$ & $\begin{array}{c}\text { Persentase } \\
\%\end{array}$ \\
\hline Larutan penyegar & 3 & 9.09 \\
Obat oles & 19 & 57,58 \\
Obat kumur & 5 & 15,15 \\
Vitamin & 6 & 18,18 \\
\hline Total & 33 & 100 \\
\hline
\end{tabular}

\section{PEMBAHASAN}

Responden dalam penelitian ini berjumlah 61 orang, yang terdiri dari 52 responden $(85,2 \%)$ berjenis kelamin perempuan dan 9 responden $(14,8 \%)$ berjenis kelamin laki-laki. Dari hasil penelitian dijumpai, perempuan cenderung lebih banyak mengalami SAR dengan presentase $80,77 \%$ sedangkan lakilaki 77,78\%, ini sesuai dengan penelitian Ship (1972), Axell dan Henricsson (1985), dan Fahmy (1976) yang menyatakan bahwa wanita lebih cenderung mengalami SAR dari pada pria. ${ }^{2}$

Hasil penelitian pada tabel 1 menunjukan bahwa, SAR yang terjadi karena penggunaan alat ortodonsi cekat sangat tinggi yaitu mencapai 80,3\%. Stomatitis Aftosa Rekuren yang terjadi disebabkan oleh trauma dari komponen alat ortodonsi cekat itu sendiri. Penelitian dari Tahan Banuarea, tentang Prevalensi terjadinya SAR pada mahasiswa Universitas Sumatera Utara yang berpengalaman SAR tahun 2009 menunjukkan bahwa, faktor pencetus terjadinya SAR tertinggi yaitu trauma dengan persentasi $50,27 \%$, sementara dari trauma karena penggunaan alat ortodonsi cekat hanya $8,33 \%,{ }^{8}$ sehingga diperoleh perbandingan antara penelitian sebelumnya dengan penelitian ini bahwa, penggunaan alat ortodonsi cekat merupakan salah satu faktor pencetus yang sangat berpengaruh terhadap terjadinya SAR. Data hasil penelitian pada tabel 2 dan 3 dijumpai, sebagian besar 
responden menggunakan alat ortodonsi cekat selama > 2 tahun dengan presentasi $29,51 \%$, dengan frekuensi terjadinya SAR tertinggi yaitu sebulan sekali dengan presentase $44,44 \%$ dan terkecil yaitu tidak teratur $22,22 \%$, dan sebagian kecil responden menggunakan alat ortodonsi cekat selama $<1$ bulan dengan presentase $6,56 \%$ dengan frekuensi terjadinya SAR yaitu 2-4 kali $25 \%$. Stomatitis Aftosa Rekuren merupakan penyakit oral yang terjadi secara berulang. ${ }^{1}$ Komponen-komponen alat ortodonsi cekat dapat menimbulkan iritasi dalam rongga mulut apalagi ketika terjadi trauma. Luka yang terjadi akibat trauma dapat berkembang menjadi ulkus SAR. ${ }^{7}$ Stomatitis Aftosa Rekuren kemungkinan tidak terjadi karena kondisi mulut pada saat penggunaan alat ortodonsi cekat baik, ataupun pada saat terjadinya trauma pasien secepatnya melakukan antisipasi perawatan sendiri misalnya menggunakan vitamin dan obat oles pada saat terjadi luka di mukosa mulut sehingga tidak berkembangnya ulkus SAR. Etiologi memang belum diketahui secara jelas tetapi ada beberapa faktor pemicu terjadinya SAR, salah satunya yaitu penggunaan alat ortodonsi cekat. $^{7,9}$

Beberapa responden mengalami SAR pada saat selesai mengganti alat ortodonsi cekatnya, dan ada juga yang mengalami SAR secara tidak teratur. Hasil penelitian pada tabel 4 menunjukkan bahwa, waktu munculnya SAR tertinggi yaitu tidak teratur dengan presentase $48,98 \%$ dan terendah yaitu 6 bulan setelah pemasangan alat ortodonsi cekat $6,12 \%$. Stomatitis Aftosa Rekuren yang terjadi, biasanya disebabkan oleh trauma dari kawat atau bracket yang mengenai mukosa mulut baik di bagian labial, bukal dan lingual. Hal ini bisa terjadi akibat pemasangan komponen ortodonsi cekat yang kurang baik, seperti pada penggunaan kawat yang terlalu panjang atau komponen lain yang menyebabkan terjadinya trauma, misalnya bracket, archwire, ligature wire, loop dan sebagainya ${ }^{7}$. Oleh karena itu sebagian besar responden mengalami SAR secara tidak teratur, karena SAR yang muncul tergantung trauma dari penggunaan alat ortodonsi cekat tersebut.

Stomatitis Aftosa Rekuren sering muncul di daerah yang tidak berkeratin seperti di pipi, bibir dan dasar lidah. ${ }^{10}$ Hasil penelitian pada Tabel 5 menunjukkan bahwa, lokasi SAR yang paling sering terkena yaitu mencapai $48,98 \%$ di mukosa pipi dan bibir sedangkan di lidah hanya $2,04 \%$. Trauma mekanis seperti penggunaan alat ortodonsi cekat dapat menyebabkan ulser pada mukosa labial, bukal dan lateral lidah. ${ }^{5}$ Stomatitis Aftosa Rekuren yang terjadi di mukosa pipi dan bibir, disebabkan oleh trauma dari komponenkomponen alat ortodonsi cekat yang berhadapan dengan bagian labial dan bukal mulut, seperti bracket yang menempel atau kawat yang tajam dan terlalu panjang. Sedangkan SAR yang terjadi di bagian lidah, biasanya disebabkan oleh trauma dari komponen alat ortodonsi cekat yang berhadapan dengan bagian lingual mulut, seperti lingual arch. Bracket atau kawat yang tertekan terus menerus pada mukosa dapat menimbulkan peradangan atau pendarahan dibawah epitel yang menyebabkan lesi eksofilik tanpa fibrosis.

Stomatitis Aftosa Rekuren dapat sembuh sendiri dalam waktu 7-14 hari tanpa dilakukan pengobatan. ${ }^{3,11}$ Banyak pasien yang menderita SAR tidak melakukan pengobatan secara berkala untuk mengurangi frekuensi terbentuknya ulser. ${ }^{10,12}$ Hasil penelitian pada tabel 6 menunjukkan bahwa, sebanyak $30,61 \%$ responden membiarkan tanpa obat ketika mengalami SAR. Data pada tabel 7 dijumpai, sebagian besar responden menjawab $<1$ minggu masa penyembuhan SAR dan tidak ada responden menjawab $>2$ minggu. Besar kemungkinan SAR yang pernah dialami oleh responden selama menggunakan alat ortodonsi cekat yaitu SAR tipe minor. Stomatitis Aftosa Rekuren tipe minor merupakan yang paling umum ditemukan. Kurang lebih $80-85 \%$ pasien yang memiliki ulser ini. Ulkus akan ditutup oleh eksudat fibrin kekuningan yang bertahan selama 7 hingga 14 hari. ${ }^{11}$

Berdasarkan data pada tabel 6 diketahui, sebanyak $67,35 \%$ responden melakukan perawatan dengan mengobati sendiri ketika mengalami SAR, sedangkan 2,04\% responden ke dokter umum dan tidak ada responden yang melakukan perawatan ke dokter gigi. Penelitian ini menunjukkan, sebagian besar responden peduli terhadap kesehatan mulutnya, walaupun melakukan pengobatan 
sendiri tanpa ke dokter gigi. Biasanya dokter gigi memberikan saran tentang cara perawatan dan pengobatan pada saat pasien melakukan kontrol pemasangan alat ortodonsinya. Oleh karena itu, pasien tidak harus ke dokter gigi ketika terjadi trauma kecil yang menimbulkan SAR. Beberapa pasien melakukan perawatan untuk mengurangi frekuensi SAR dan mengurangi rasa sakit. ${ }^{11}$ Meskipun SAR bisa sembuh sendiri dalam waktu 7-14 hari namun terasa sakit. Bagaimanapun juga tujuan penanganan SAR mencakup penanganan rasa sakit dan gangguan fungsional dengan mengatasi respon inflamasi dan mengurangi frekuensi rekurensi atau mencegah timbulnya ulkus baru. ${ }^{13}$

Data hasil penelitian pada Tabel 8 menunjukkan bahwa, dari $66,07 \%$ responden yang mengobati sendiri, terbanyak menggunakan obat oles dengan presentase $57,58 \%$, vitamin $18,18 \%$, obat kumur $15,15 \%$, dan larutan penyegar 9,09\%. Terapi topikal seperti obat oles dan obat kumur dapat membantu meringankan inflamasi contohnya larutan ekstrak chamomile. ${ }^{14}$ Obat kumur klorheksidin glukonat dan vitamin Bkompleks dapat membantu mengurangi durasi SAR serta mencegah munculnya ulkus baru. ${ }^{5}$ Keuntungan terapetik lain juga dapat diperoleh dari obat kumur yang mengandung betametason. Sebuah studi menunjukkan aplikasi topikal diklofenak $3 \%$ pada hialuronan 2,5\% menunjukkan penurunan rasa sakit yang signifikan. Terapi lokal dengan tetrasiklin dapat mengurangi durasi dan rasa sakit pada SAR secara efektif. Vitamin B12 umum digunakan untuk pengobatan SAR. Vitamin B12 merupakan pengobatan paling murah, sederhana, dengan risiko yang sangat rendah, dan efektif. ${ }^{15}$ Berdasarkan hasil penelitian tersebut, dapat dilihat bahwa penanganan responden baik terhadap SAR yang mereka derita.

\section{SIMPULAN}

Angka rekurensi SAR terhadap lama penggunaan alat ortodonsi cekat, sebanyak $29,51 \%$ menggunakan alat selama $>2$ tahun yang angka rekurensinya mencapai $36,73 \%$ pada pilihan tidak teratur. Lokasi SAR yang sering terkena yaitu pada mukosa pipi dan bibir yaitu $48,98 \%$. Mahasiswa pengguna alat ortodonsi cekat ketika mengalami SAR paling sering melakukan perawatan dengan mengobati sendiri.

\section{SARAN}

Dari penelitian ini diharapkan kepada institusi dalam hal ini BP-RSGM untuk dapat melakukan upaya penyuluhan mengenai pentingnya menjaga kesehatan gigi dan mulut selama perawatan ortodonsi cekat untuk menghindari munculnya penyakit mulut seperti SAR. Selain itu, disarankan juga kepada pasien khususnya pengguna alat ortodonsi cekat, agar rutin mengontrol ke dokter gigi selama perawatan ortodonsi cekat, sehingga masalah dalam rongga mulut seperti SAR dapat dihindari.

\section{DAFTAR PUSTAKA}

1. Nabhikan A, Ravikumarhr M, Kallallibn M, Choprass M. Management of Reccurent Aphthous Stomatitis with Chlorhexidine Gluconate Mouthwash and Vitamin B-Complex; Pakistan Oral \& Dent J. 2012; 8: vol 32 :2.

2. Jurge S, Kuffer R, Scully C, Porter SR. Reccurent Aphthous Stomatitis. Oral Dis [serial online]. 2006 [cited 2013 April 18]; 12 (1) : 1-21. Available from: http://www.ncbi.nlm.nih.gov/pubmed/16 390463

3. Scully C, de Almeida OP, Bagan J, Dioz PD, Taylor AM. Oral Medicine and Pathology at a Glance. West Sussex: Wiley-Blackwell. 2010. p. 56-7.

4. Fernandes R, Tucky T, Lam P, Allidina S, Sharifi S, Nia D. The best Treatment for Aphthous Ulcers: An EvidenceBassed Study of Literature. MeSH Dent J. 2006; 7: 1-7.

5. Gandolfo S, Scully C, Carrozzo M. Oral Medicine. Edinburg. New York. Oxford. St Louis. Sydney Toronto: Churchill livingstone; 2005. p. 447-51.

6. Hurlbutt M, Thomsen L. Demystifying Reccurent Oral Ulceration. ADA CERP PennWell [serial online]. 2007 [cited 2013 April 19]; 4: 1-9. Available from: http://www.ineedce.com/courses/1430/P DF/DemystRecurOralUlceratns.pdf

7. Belly Y, Prihandini IWS. Efek Pasta Gigi Non Detergen Pada Gingivitis dan 
Stomatitis Aphtosa Pemakai Alat Cekat: MIKGI. 2003; 10(10)

8. Banuarea T. Prevalensi terjadinya Stomatitis Aftosa Rekuren (SAR) pada mahasiswa Universitas Sumatera Utara yang berpengalaman SAR: [serial online] 2009. [cited 2013 Juni 18]. Available from

http://repository.usu.ac.id/bitstream/1234 56789/8360/1/09E02835.pdf

9. Samar B, Faleh S, Zouhair A. Hematologic Status in Patient with Reccurent Aphthous Stomatitis in Jordan: Saudi Med J: 2006; 27 (3): 381-384.

10. Koybasi S, Parlak AH, Serin E, Yilmaz F, Serin D. Reccurent Aphthous Stomatitis: Investigation of Possible Etiologic Factors. Am J Otolaryngol [serial online]. 2006 [cited 2013 April 22]; 27 (4): 229-32. Available from: http://www.ncbi.nlm.nih.gov/pubmed/16 798397.

11. Neville BW, Damm DD, Allen CM, Bouquot JE. Oral and Maxillofacial Pathology $3^{\text {rd }}$ ed. Philadelphia: ElsevierSaunders; 2009. p. 285-90.

12. Scully C, Gorsky M, Lozada-Nur F. The Diagnosis and Management of Reccurent Aphthous Stomatitis: A Consensus Approach. J Am Dent Assoc. 2003; 134: 200-7.

13. Michael A.O. Lewis, Richard C.K. Jordan. A Color Handbook of Oral Medicine [serial online]. 2004 [cited 2013 Juni 20]; p. 24-5. Available from: http://books.google.co.id/books?id=yRX NBf0CGMwC\&printsec $=$ frontcover\&dq =inauthor:\%22Richard+C.+K.+Jordan\% 22\&hl=id\&sa=X\&ei=KOBWUsObCcnil AWehICoBQ\&ved=0CC0Q6AEwAA\#v =onepage \&q\&f=false

14. Altenburg A, Zouboulis CC. Current Concepts in the Treatment of Recurrent Aphtous Stomatitis. Skin Therapy Letter. 2008; 13 (7): 1-4.

15. Volkov I, Rudoy I, Abu-Rabia U, Masalha T, Masalha R. Case Report: Recurrent Aphtous Stomatitis Responds to Vitamin B12 Treatment. Can Fam Physician. 2005; 51: 844-5. 